\title{
Simultaneous identifications of the minimum effective dose in each of several groups
}

\author{
SHOW-LI JAN*†, YUH-ING CHEN $\ddagger$ and GWOWEN SHIEH§ \\ $\dagger$ Department of Applied Mathematics, Chung Yuan Christian University, Chungli, \\ 32023, Taiwan, R.O.C. \\ \$National Central University \\ §National Chiao Tung University
}

(Received 20 October 2004; in final form 8 May 2005)

\begin{abstract}
One primary goal in dose-response studies for drug development is to identify the minimum effective dose (MED) which is the lowest dose level with an effect that exceeds that of the zero dose control. In this paper, we consider step-down closed testing procedures on the basis of pairwise and Helmert contrasts suggested by Tamhane et al. [Tamhane, A.C., Hochberg, Y., and Dunnett, C.W., 1996, Multiple test procedures for dose finding. Biometrics, 52, 21-37.] for the situation where one wishes to make all such MED identifications simultaneously in each of several groups. An example is given to illustrate the proposed tests. The Monte Carlo studies are further implemented to compare the relative error rate and power performances of the proposed tests.
\end{abstract}

Keywords: Dose-response study; Helmert contrasts; Pairwise contrasts; Simultaneous inference; Step-down closed test.

\section{Introduction}

In toxicological and drug development studies, a common problem is to investigate the effect of a compound. For this purpose, a dose-response experiment is often conducted in a oneway layout in which several increasing dose levels of the compound, including a zero dose or a placebo to serve as a control, are administered to separate groups of subjects. In drug development studies, the major concern is to identify the minimum effective dose, denoted by MED [1], where the MED is defined to be the lowest dose level with a mean, larger than that of the zero dose control.

Generally, in a one-way layout, the inference about the MED is made by comparing various dose groups with a control. Among the available procedures, the ones proposed by Dunnett [2], Williams [3, 4] and Ruberg [1], are most popular. Note that Williams' procedure is based on the isotonic regression estimators of ordered means, implemented into a step-down closed testing scheme [5], whereas both Dunnett and Ruberg employed single-step multiple testing

\footnotetext{
*Corresponding author. Email: sljan@math.cycu.edu.tw 
procedures based on different contrasts of sample means. Owing to the fact that contrasts of sample means are more convenient to compute than the isotonic regression estimators under ordered restriction, and multi-step multiple tests are more powerful than the related single-step multiple tests, Tamhane et al. [6] further considered some stepwise closed testing procedures based on a variety of contrasts for the dose-finding problem. It was pointed out that the procedures based on the so-called step and basin contrasts proposed by Ruberg [1] do not control the familywise error rate (FWE). Moreover, the step-down procedures generally dominate the related step-up procedures. Therefore, Tamhane et al. [6] finally suggested pairwise and Helmert contrasts incorporated into the proposed step-down testing scheme.

In medical and biological researches, however, the experimenters often encounter the multigroup situation due to different gender, age or compounds, where there are $r$ groups, each consisting of $c$ active treatments and one control treatment. In the absence of interaction between treatment and group, one can use the original Dunnett procedure, but with average over all groups, for identifying the treatments which are better than or different from the control. When the interaction is present, however, Cheung and Holland [7, 8] extended Dunnett's test and proposed a single-step procedure to identify simultaneously the treatments which are more effective than or different from the related control in each of the $r$ groups. Cheung and Holland [9] further suggested an extension of Dunnett and Tamhane's [10] step-down closed testing procedure to the multi-group problem, which is more powerful than their extension of Dunnett's test.

Note that, when the multi-group situation is involved in a drug development study, the MEDs of interest may very well vary in different groups. Therefore, the simultaneous identifications of the MED in each of the groups under study would be of great practical importance. In this paper, we extend the step-down closed testing scheme proposed by Tamhane et al. [6] on the basis of pairwise and Helmert contrasts to the multi-group problem. To provide with a measure of the strength of evidence for the simultaneous MED identifications, we further suggest a modification of the step-down closed testing scheme by using the related adjusted $p$-values [11].

Section 2 gives the notation and description of the multi-group problem. Section 3 proposes two sets of contrasts for the simultaneous identifications of the MED. The concept of the stepdown testing scheme is described both in its classical version and $p$-value version, where the exact integration and a convenient approximation of the computations of the critical constants and $p$-values are discussed. Section 4 presents a numerical example to illustrate the proposed step-down procedures. Section 5 shows the results of a Monte Carlo study comparing the proposed tests under the null hypothesis and a variety of alternative hypotheses. Finally, section 6 gives conclusions and recommendations.

\section{Preliminaries}

Assume the existence of $r$ groups. Denote a set of increasing dose levels by $0,1,2, \ldots, c$, where 0 corresponds to the zero dose level (or placebo control). For $i=1, \ldots, r$ and $j=0,1, \ldots, c$, let $X_{i j k}$ denote the $k$ th observation on the $j$ th dose level in the $i$ th group, where $k=1, \ldots, n$ for all $(i, j)$. We assume that all observations $X_{i j k}$ are mutually independent with $X_{i j k} \sim N\left(\mu_{i j}, \sigma^{2}\right), i=1, \ldots, r, j=0,1, \ldots, c$, and $k=1, \ldots, n$. Here $\mu_{i j}$ represents the effect of the $j$ th dose level in the $i$ th group. Define

$$
\bar{X}_{i j}=\frac{1}{n} \sum_{k=1}^{n} X_{i j k} \quad \text { and } \quad S^{2}=\sum_{i=1}^{r} \sum_{j=0}^{c} \sum_{k=1}^{n} \frac{\left(X_{i j k}-\bar{X}_{i j}\right)^{2}}{f} \text {, }
$$


where $f=r(c+1)(n-1)$. Hence the sample means $\bar{X}_{i j}$ are mutually independent with $\bar{X}_{i j} \sim N\left(\mu_{i j}, \sigma^{2} / n\right)$. The pooled sample variance $S^{2}$, providing an unbiased estimator of the common variance $\sigma^{2}$ based on $f$ degrees of freedom (d.f.), is independent of $\bar{X}_{i j}$ with $S^{2} \sim \sigma^{2} \chi_{f}^{2} / f$.

Define the MED for the $i$ th group as $\operatorname{MED}_{i}=\min \left\{j: \mu_{i j}>\mu_{i 0}\right\}, i=1, \ldots, r$. In this paper, we wish to identify $\mathrm{MED}_{i}$ simultaneously. The problem is formulated as a sequence of hypotheses testing problems

$$
\begin{aligned}
\mathrm{H}_{0 i j_{i}}: \mu_{i 0} & =\mu_{i 1}=\cdots=\mu_{i j_{i}} \quad \text { vs. } \quad \mathrm{H}_{1 i j_{i}}: \mu_{i 0}=\mu_{i 1}=\cdots=\mu_{i, j_{i}-1}<\mu_{i j_{i}}, \\
j_{i} & =1, \ldots, c \quad \text { and } i=1, \ldots, r .
\end{aligned}
$$

If $j_{i}^{*}$ is the smallest $j_{i}$ for which $\mathrm{H}_{0 i j_{i}}$ is rejected, then the $j_{i}^{*}$ th dose is identified to be the MED for the $i$ th group, that is, $\widehat{\operatorname{MED}}_{i}=j_{i}^{*}$.

As noted in ref. [12], the family of hypotheses $H=\left\{\left(H_{01 j_{1}}, \ldots, H_{0 r j_{r}}\right): 1 \leq j_{1}, \ldots, j_{r} \leq c\right\}$, where $\left(H_{01 j_{1}}, \ldots, H_{0 r j_{r}}\right)$ represents the hypotheses $H_{01 j_{1}}, \ldots, H_{0 r j_{r}}$ are simultaneously tested, is closed under intersection in the sense that $\left(H_{01 j_{1}}, \ldots, H_{0 r j_{r}}\right) \in H$ and $\left(H_{01 j_{1}^{\prime}}, \ldots, H_{0 r j_{r}^{\prime}}\right) \in$ $H$ imply that $\left(H_{01 j_{1}} \cap H_{01 j_{1}^{\prime}}, \ldots, H_{0 r j_{r}} \cap H_{0 r j_{r}^{\prime}}\right) \in H$. Hence, an $\alpha$-level closed procedure that includes separate $\alpha$-level tests of individual $\left(H_{01 j_{1}}, \ldots, H_{0 r j_{r}}\right)$, applied in a step-down manner can be employed in finding the $\mathrm{MED}_{i}$ simultaneously. Moreover, the closed testing scheme strongly controls the FWE, which is defined as $\mathrm{FWE}=\mathrm{P}\left\{\right.$ at least one true $\mathrm{H}_{0 i j_{i}}$ is rejected . The step-down procedures proposed in section 3 are of closed type and, hence, control the FWE strongly.

\section{The proposed step-down procedures}

\subsection{Procedures based on contrasts}

For testing a hypothesis $\mathrm{H}_{0 i j}$ of (1), a contrast of the following general form is used: $C_{i j}=$ $a_{0 j} \bar{X}_{i 0}+a_{1 j} \bar{X}_{i 1}+\cdots+a_{c j} \bar{X}_{i c}$, where $\sum_{s=0}^{c} a_{s j}=0$. The corresponding $t$-statistic is given by

$$
T_{i j}=\frac{C_{i j}-E\left(C_{i j}\right)}{\sqrt{\operatorname{Var}\left(C_{i j}\right)}}=\frac{\sum_{s=0}^{c} a_{s j}\left(\bar{X}_{i s}-\mu_{i s}\right)}{S \sqrt{\sum_{s=0}^{c} a_{s j}^{2} / n}}, \quad 1 \leq i \leq r, \quad 1 \leq j \leq c .
$$

The critical points of the procedure depend on the joint distribution of $T_{i j}$. Letting $\mathbf{T}_{\mathbf{i}}=\left(T_{i 1}, \ldots, T_{i c}\right)$, we note that, under $\mathrm{H}_{0 i c}, \mathbf{T}_{\mathbf{i}}$ has a general $c$-variate $t$-distribution with $f$ d.f. and associated correlation matrix $A=\left\{\rho_{j j^{\prime}}\right\}$, where $\rho_{j j^{\prime}}$ is the correlation coefficient between the $j$ th and the $j^{\prime}$ th contrasts, $1 \leq j \neq j^{\prime} \leq c$. Similarly, under $\mathrm{H}_{0 i c}$, $i=1, \ldots, r,\left(T_{11}, \ldots, T_{1 c}, \ldots, T_{r 1}, \ldots, T_{r c}\right)=\left(\mathbf{T}_{\mathbf{1}}, \ldots, \mathbf{T}_{\mathbf{r}}\right)$ has a $r \times c$-variate $t$-distribution with $f$ d.f. and correlation matrix $\mathrm{R}_{r \times c}=\operatorname{diag}(\mathrm{A}, \ldots, \mathrm{A})[13,14]$.

In this paper, we consider the following two sets of contrasts:

(1) Pairwise (P) contrasts. The $j$ th pairwise contrast is defined by

$$
a_{s j}=\left\{\begin{aligned}
-1, & s=0, \\
1, & s=j, \quad 1 \leq j \leq c . \\
0, & \text { o.w. }
\end{aligned}\right.
$$


Thus, under $H_{0 i c}$, we can rewrite (2) as

$$
T P_{i j}=\frac{\bar{X}_{i j}-\bar{X}_{i 0}}{S \sqrt{2 / n}}, \quad 1 \leq i \leq r \text { and } 1 \leq j \leq c .
$$

The correlation coefficients are given by $\rho_{j j^{\prime}}=1 / 2,1 \leq j \neq j^{\prime} \leq c$. And hence, under $\mathrm{H}_{0 i c}, i=1, \ldots, r,\left(T P_{11}, \ldots, T P_{1 c}, \ldots, T P_{r 1}, \ldots, T P_{r c}\right)$ has a $r \times c$-variate $t$-distribution with $f$ d.f. and correlation matrix $\mathrm{R}_{r \times c}=\operatorname{diag}(\mathrm{A}, \ldots, \mathrm{A})$, where

$$
A=\left(\begin{array}{ccc}
1 & & 1 / 2 \\
& \ddots & \\
1 / 2 & & 1
\end{array}\right)
$$

(2) Helmert $(\mathrm{H})$ contrasts. The $j$ th Helmert contrast is defined by

$$
a_{s j}=\left\{\begin{aligned}
-1, & s=0,1, \ldots, j-1 \\
j, & s=j, \quad 1 \leq j \leq c . \\
0, & \text { o.w, }
\end{aligned}\right.
$$

This contrast compares the $j$ th dose level mean with the average of all the lower dose level means, including the zero dose control. In this case, under $\mathrm{H}_{0 i c}$, (2) specifies to

$$
T H_{i j}=\frac{j \bar{X}_{i j}-\left(\bar{X}_{i 0}+\cdots+\bar{X}_{i, j-1}\right)}{S \sqrt{j(j+1) / n}}, \quad 1 \leq i \leq r, \quad \text { and } \quad 1 \leq j \leq c .
$$

These contrasts are mutually orthogonal and hence $\rho_{j j^{\prime}}=0,1 \leq j \neq j^{\prime} \leq c$. Therefore, under $\mathrm{H}_{0 i c}, i=1, \ldots, r,\left(T H_{11}, \ldots, T H_{1 c}, \ldots, T H_{r 1}, \ldots, T H_{r c}\right)$ has a $r \times c$-variate $t$ distribution with $f$ d.f. and correlation matrix $R_{r \times c}=I_{r \times c}$, the identity matrix.

\subsection{Step-down testing scheme}

We now show how to extend the step-down procedures proposed by Tamhane et al. [6] for identifying MED in a one-way layout to the situation where one wishes to make all such MED identifications simultaneously in each of $r$ groups [12].

We shall describe the step-down procedure first in its classical version, based on critical constants for a specified $\alpha$-level. Let $T_{r \times c, f, R_{r \times c}}^{\alpha}$ be the upper $\alpha$ th percentile of $T_{(r \times c)}=$ $\max \left\{T_{i j}: 1 \leq i \leq r, 1 \leq j \leq c\right\}$, and let $t_{(r \times c)}$ be the observed maximum of $T_{(r \times c)}$. At the first step, let $c_{1 i}=c$ be the number of hypotheses to be tested in the $i$ th group, $i=1, \ldots, r$, and $k_{1}=\sum_{i=1}^{r} c_{1 i}$ be the total number of hypotheses still to be tested. Compute $t_{\left(k_{1}\right)}$ and define $\left(g\left(k_{1}\right), d\left(g\left(k_{1}\right)\right)\right)$, which represents the group and dose level, to be the antirank vector of $t_{\left(k_{1}\right)}$, i.e., $t_{\left(k_{1}\right)}=t_{g\left(k_{1}\right), d\left(g\left(k_{1}\right)\right)}$. If $t_{\left(k_{1}\right)} \geq T_{k_{1}, f, R_{k_{1}}}^{\alpha}$, then reject $\mathrm{H}_{0 g\left(k_{1}\right) j}, j=d\left(g\left(k_{1}\right)\right), \ldots, c_{1 g\left(k_{1}\right)}$, and go to the second step with $k_{2}=\sum_{i=1}^{r} c_{2 i}$, where $c_{2 i}=d\left(g\left(k_{1}\right)\right)-1$ if $i=g\left(k_{1}\right)$ and $c_{1 i}$ otherwise. Otherwise, stop testing and accept all null hypotheses. In general, at the $\ell$ th step, set $k_{\ell}=\sum_{i=1}^{r} c_{\ell i}$, where $c_{\ell i}=d\left(g\left(k_{\ell-1}\right)\right)-1$ if $i=g\left(k_{\ell-1}\right)$ and $c_{\ell-1, i}$ otherwise. Let $\left(g\left(k_{\ell}\right), d\left(g\left(k_{\ell}\right)\right)\right)$ be the antirank vector of $t_{\left(k_{\ell}\right)}$, where $t_{\left(k_{\ell}\right)}$ is the observed maximum of the corresponding $t$-statistics associated with the $k_{\ell}$ null hypotheses. If $t_{\left(k_{\ell}\right)} \geq T_{k_{\ell}, f, R_{k_{\ell}}}^{\alpha}$, then reject $\mathrm{H}_{0 g\left(k_{\ell}\right) j}, j=d\left(g\left(k_{\ell}\right)\right), \ldots, c_{\ell g\left(k_{\ell}\right)}$; otherwise, stop testing. When testing stops, say at the $m$ th step, estimate the $\operatorname{MED}_{i}$ as $c_{m i}+1$, that is, $\widehat{\operatorname{MED}}_{i}=c_{m i}+1, i=1, \ldots, r$. 
Next we describe how to apply the concept of adjusted $p$-values, proposed by Dunnett and Tamhane [10], to this step-down procedure. In general, at the $\ell$ th step for testing $\mathrm{H}_{0\left(k_{\ell}\right)}$, i.e., $H_{0 g\left(k_{\ell}\right) d g\left(k_{\ell}\right)}$, first compute the probability

$$
\begin{aligned}
p_{\ell}^{\prime} & =\mathrm{P}\left\{\text { at least one } T_{a} \geq t_{\left(k_{\ell}\right)}, a=1, \ldots, k_{\ell}\right\} \\
& =\mathrm{P}\left\{\max _{\substack{1 \leq j \leq c_{\ell} \\
1 \leq i \leq r}} T_{i j} \geq t_{\left(k_{\ell}\right)}\right\}, \quad \ell=1,2, \ldots
\end{aligned}
$$

Then define the $p$-value for $\mathrm{H}_{0\left(k_{\ell}\right)}$ to be

$$
p_{\ell}=\max \left(p_{\ell}^{\prime}, p_{\ell-1}^{\prime}, \ldots, p_{1}^{\prime}\right), \quad \ell=1,2, \ldots
$$

On the basis of these $p$-values, hypotheses tests can be conducted at any fixed specified $\alpha$-level by comparing any $p_{\ell}$ with $\alpha$ and rejecting $\mathrm{H}_{0 g\left(k_{\ell}\right) j}, j=d\left(g\left(k_{\ell}\right)\right), \ldots, c_{\ell g\left(k_{\ell}\right)}$ if $p_{\ell} \leq \alpha, \ell=1,2, \ldots$. Note that the $p$-values are monotonically ordered, that is, $p_{1} \leq$ $p_{2} \leq \cdots$. Thus if $p_{\ell}>\alpha$ and hence $\mathrm{H}_{0\left(k_{\ell}\right)}$ is accepted, then monotonicity ensures acceptance also of $\mathrm{H}_{0(1)}, \ldots, \mathrm{H}_{0\left(k_{\ell}-1\right)}$.

To conclude this section, we discuss the methods for calculation of critical constants and $p$-values. Among others, Somerville [15-17] and Genz and Bretz [18-20] have developed exact integration methods for the calculation of these values. (The SAS and FORTRAN programs by Genz and Bretz are available from the websites with URL http://www.bioinf.uni-hannover.de/mcp_home/software.html and URL http://www.sci.wsu.edu/math/faculty/genz/homepage, respectively.) While exact methods exist for these computations, it is sometimes necessary for practical purpose to consider some simple and convenient approximations [21-24]. To this end, we introduce the use of the SAS function PROBMC along with some approximations for computing the critical constants and $p$-values of the proposed procedures. When $\left(T_{1}, \ldots, T_{k}\right)$ has a $k$-variate $t$-distribution with product correlation structure $\rho_{i j}=\lambda_{i} \lambda_{j},-1<\lambda_{i}, \lambda_{j}<1$, the critical constants and $p$-values for $T_{(k)}=\max \left(T_{1}, \ldots, T_{k}\right)$ can be easily obtained, through computing

$$
\text { PROBMC('DUNNETT1', } \left.\cdot, 1-\alpha, f, k_{\ell}, \lambda_{1}, \ldots, \lambda_{k_{\ell}}\right),
$$

and

$$
\left.1 \text { - PROBMC('DUNNETT1', } t_{\left(k_{\ell}\right)}, \cdot, f, k_{\ell}, \lambda_{1}, \ldots, \lambda_{k_{\ell}}\right),
$$

respectively. For Helmert procedure, the correlation matrix $R_{r \times c}$ is an identity matrix, thus formulas (8) and (9) can be applied readily. (A small positive number substituted for 0 in $\lambda_{i}$ may be used to improve the convergence of the PROBMC method.) For pairwise procedure, the $R_{r \times c}$ matrix is not of product correlation structure, moreover, it is changing at each step of testing; in this case, we consider a convenient approximation by replacing $\rho_{i j}$ with their arithmetic average $\bar{\rho}$ (computed from $R_{r \times c}$ ) when applying formulas (8) and (9) for the calculations. Due to the nature of the correlation matrix $R_{r \times c}$, where most entries are zero, this approximation is simple and quite acceptable. The approximations for pairwise and Helmert procedures are justified through an example in the next section.

\section{An example}

In this section, we illustrate the step-down procedures using a drug-dose-response data set which was collected for a study in pharmacochemistry [25]. To investigate the effect of drug and dose on the analgesic potency, a two-way layout was implemented which involved five 
drug groups, including three mixed-type opioids (groups 1, 3 and 4), one placebo containing $0.9 \%$ saline solution (group 2) and one opioid antagonist (group 5), and five doses, ED, $\mathrm{ED}_{10}$, $\mathrm{ED}_{20}, \mathrm{ED}_{40}$ and $\mathrm{ED}_{80}$ determined from an earlier in vitro trial. For each drug group and dose, $n=10$ mice were used. The analgesic response of each mouse was measured at certain time points.

Note that the analysis results of the time-dependent analgesia under the assumption of normal distribution in ref. [25] reveal that the interaction effect between the drug group and dose is present. Therefore, the nature of analgesia is a function of the dose levels at various drug groups. In this data set, for the purpose of dose-finding, the MED among $c=4$ doses $\left(E D_{10}-E_{80}\right)$ relative to the control dose $\mathrm{ED}_{5}$ would be of interest. However, the MEDs should be identified for each drug group at each time point. Therefore, we show how to apply the step-down procedures under study to simultaneously identify the MEDs for $r=5$ drug groups based on the analgesic response measured at $10 \mathrm{~min}$ after the mouse receiving the drug. The mean values of the analgesic potency in each cell are given in table 1 , where the dose levels are recorded as $0,1,2,3,4$. The variance estimate and the associated d.f. are $s^{2}=8.825$ and $f=225$, respectively. The $t$-statistics computed by using formulas (3) and (5) are then shown in table 2.

First, considering pairwise contrasts and using $\alpha=0.05$. Here $\bar{\rho}=0.5 \times 6 \times 5 /(20 \times$ $19 / 2)=0.079$ is used at each step, the critical values and probabilities $p_{\ell}^{\prime}$ are computed, respectively, using formulas (8) and (9). The $p_{\ell}^{\prime}$ and $p_{\ell}$ probabilities in parentheses are exact values computed by using the SAS program from Benz and Bretz. The testing results are summarized in table 3 . Note that the testing stops at the 11th step, and hence estimate the

\begin{tabular}{|c|c|c|}
\hline Group & Dose & Mean \\
\hline & 0 & 7.07 \\
\hline & 1 & 9.56 \\
\hline & 2 & 14.78 \\
\hline & 3 & 21.62 \\
\hline & 4 & 23.16 \\
\hline & 0 & 1.25 \\
\hline & 1 & 1.26 \\
\hline & 2 & 1.08 \\
\hline & 3 & 1.04 \\
\hline & 4 & 1.39 \\
\hline & 0 & 6.91 \\
\hline & 1 & 9.12 \\
\hline & 2 & 15.13 \\
\hline & 3 & 24.63 \\
\hline & 4 & 22.63 \\
\hline & 0 & 2.79 \\
\hline & 1 & 1.85 \\
\hline & 2 & 3.48 \\
\hline & 3 & 5.75 \\
\hline & 4 & 11.66 \\
\hline & 0 & 18.26 \\
\hline & 1 & 27.50 \\
\hline & 2 & 40.19 \\
\hline & 3 & 46.04 \\
\hline & 4 & 57.21 \\
\hline
\end{tabular}


Table 2. $t$-Statistics for pairwise and Helmert contrasts.

\begin{tabular}{lrrr}
\hline & & \multicolumn{2}{c}{$t$-Statistcs } \\
\cline { 3 - 4 } Group & Dose & Pairwise & Helmert \\
\hline 1 & 1 & 1.87 & 1.87 \\
1 & 2 & 5.80 & 5.62 \\
1 & 3 & 10.95 & 10.28 \\
1 & 4 & 12.11 & 9.43 \\
2 & 1 & 0.01 & 0.01 \\
2 & 2 & -0.13 & -0.15 \\
2 & 3 & -0.16 & -0.14 \\
2 & 4 & 0.11 & 0.22 \\
3 & 1 & 1.66 & 1.66 \\
3 & 2 & 6.19 & 6.18 \\
3 & 3 & 13.34 & 13.13 \\
3 & 4 & 11.83 & 8.27 \\
4 & 1 & -0.71 & -0.71 \\
4 & 2 & 0.52 & 1.01 \\
4 & 3 & 2.23 & 2.81 \\
4 & 4 & 6.68 & 7.80 \\
5 & 1 & 6.96 & 6.96 \\
5 & 2 & 16.51 & 15.05 \\
5 & 3 & 20.91 & 16.03 \\
5 & 4 & 29.32 & 23.05 \\
\hline & & &
\end{tabular}

Table 3. Testing results for using pairwise contrasts $(f=225, \rho=\bar{\rho}=.079)$.

\begin{tabular}{|c|c|c|c|c|c|c|c|c|}
\hline $\operatorname{Step}(\ell)$ & $k_{\ell}$ & $\left(c_{\ell 1}, c_{\ell 2}, c_{\ell 3}, c_{\ell 4}, c_{\ell 5}\right)$ & $t_{\left(k_{\ell}\right)}$ & Group & Dose & $T_{k_{\ell}, f, \rho}^{.05}$ & $p_{\ell}^{\prime}$ & $p_{\ell}$ \\
\hline 1 & 20 & $(4,4,4,4,4)$ & 29.32 & 5 & 4 & 2.82 & $\begin{array}{r}.0000 \\
(.0000\end{array}$ & $\begin{array}{l}.0000 \\
.0000)\end{array}$ \\
\hline 2 & 19 & $(4,4,4,4,3)$ & 20.91 & 5 & 3 & 2.80 & $\begin{array}{r}.0000 \\
(.0000\end{array}$ & $\begin{array}{l}.0000 \\
.0000)\end{array}$ \\
\hline 3 & 18 & $(4,4,4,4,2)$ & 16.51 & 5 & 2 & 2.78 & $\begin{array}{r}.0000 \\
(.0000\end{array}$ & $\begin{array}{l}.0000 \\
.0000)\end{array}$ \\
\hline 4 & 17 & $(4,4,4,4,1)$ & 13.34 & 3 & 3 & 2.76 & $\begin{array}{r}.0000 \\
(.0000\end{array}$ & $\begin{array}{l}.0000 \\
.0000)\end{array}$ \\
\hline 5 & 15 & $(4,4,2,4,1)$ & 12.11 & 1 & 4 & 2.72 & $\begin{array}{r}.0000 \\
(.0000\end{array}$ & $\begin{array}{l}.0000 \\
.0000)\end{array}$ \\
\hline 6 & 14 & $(3,4,2,4,1)$ & 10.95 & 1 & 3 & 2.70 & $\begin{array}{r}.0000 \\
(.0000\end{array}$ & $\begin{array}{l}.0000 \\
.0000)\end{array}$ \\
\hline 7 & 13 & $(2,4,2,4,1)$ & 6.96 & 5 & 1 & 2.67 & $\begin{array}{r}.0000 \\
(.0000\end{array}$ & $\begin{array}{l}.0000 \\
.0000)\end{array}$ \\
\hline 8 & 12 & $(2,4,2,4,0)$ & 6.68 & 4 & 4 & 2.65 & $\begin{array}{r}.0000 \\
(.0000\end{array}$ & $\begin{array}{l}.0000 \\
.0000)\end{array}$ \\
\hline 9 & 11 & $(2,4,2,3,0)$ & 6.19 & 3 & 2 & 2.62 & $\begin{array}{r}.0000 \\
.0000\end{array}$ & $\begin{array}{l}.0000 \\
.0000)\end{array}$ \\
\hline 10 & 10 & $(2,4,1,3,0)$ & 5.80 & 1 & 2 & 2.58 & $\begin{array}{r}.0000 \\
(.0000\end{array}$ & $\begin{array}{l}.0000 \\
.0000)\end{array}$ \\
\hline 11 & 9 & $(1,4,1,3,0)$ & 2.23 & 4 & 3 & 2.54 & $\begin{array}{r}.1106 \\
(.1013\end{array}$ & $\begin{array}{l}.1106 \\
.1013)\end{array}$ \\
\hline
\end{tabular}


Table 4. Testing results for using Helmert contrasts $(f=\infty, \rho=.00011)$.

\begin{tabular}{|c|c|c|c|c|c|c|c|c|}
\hline $\operatorname{Step}(\ell)$ & $k_{\ell}$ & $\left(c_{\ell 1}, c_{\ell 2}, c_{\ell 3}, c_{\ell 4}, c_{\ell 5}\right)$ & $t_{\left(k_{\ell}\right)}$ & Group & Dose & $T_{k_{\ell}, f, \rho}^{.05}$ & $p_{\ell}^{\prime}$ & $p_{\ell}$ \\
\hline 1 & 20 & $(4,4,4,4,4)$ & 23.05 & 5 & 4 & 2.80 & $\begin{array}{r}.0000 \\
(.0000\end{array}$ & $\begin{array}{l}.0000 \\
.0000)\end{array}$ \\
\hline 2 & 19 & $(4,4,4,4,3)$ & 16.03 & 5 & 3 & 2.78 & $\begin{array}{r}.0000 \\
(.0000\end{array}$ & $\begin{array}{l}.0000 \\
.0000)\end{array}$ \\
\hline 3 & 18 & $(4,4,4,4,2)$ & 15.05 & 5 & 2 & 2.77 & $\begin{array}{r}.0000 \\
(.0000\end{array}$ & $\begin{array}{l}.0000 \\
.0000)\end{array}$ \\
\hline 4 & 17 & $(4,4,4,4,1)$ & 13.13 & 3 & 3 & 2.75 & $\begin{array}{r}.0000 \\
(.0000\end{array}$ & $\begin{array}{l}.0000 \\
.0000)\end{array}$ \\
\hline 5 & 15 & $(4,4,2,4,1)$ & 10.28 & 1 & 3 & 2.71 & $\begin{array}{r}.0000 \\
(.0000\end{array}$ & $\begin{array}{l}.0000 \\
.0000)\end{array}$ \\
\hline 6 & 13 & $(2,4,2,4,1)$ & 7.80 & 4 & 4 & 2.66 & $\begin{array}{r}.0000 \\
(.0000\end{array}$ & $\begin{array}{l}.0000 \\
.0000)\end{array}$ \\
\hline 7 & 12 & $(2,4,2,3,1)$ & 6.96 & 5 & 1 & 2.63 & $\begin{array}{r}.0000 \\
(.0000\end{array}$ & $\begin{array}{l}.0000 \\
.0000)\end{array}$ \\
\hline 8 & 11 & $(2,4,2,3,0)$ & 6.18 & 3 & 2 & 2.60 & $\begin{array}{r}.0000 \\
(.0000\end{array}$ & $\begin{array}{l}.0000 \\
.0000)\end{array}$ \\
\hline 9 & 10 & $(2,4,1,3,0)$ & 5.62 & 1 & 2 & 2.57 & $\begin{array}{r}.0000 \\
(.0000\end{array}$ & $\begin{array}{l}.0000 \\
.0000)\end{array}$ \\
\hline 10 & 9 & $(1,4,1,3,0)$ & 2.81 & 4 & 3 & 2.53 & $\begin{array}{r}.0224 \\
(.0240\end{array}$ & $\begin{array}{l}.0224 \\
.0240)\end{array}$ \\
\hline 11 & 8 & $(1,4,1,2,0)$ & 1.87 & 1 & 1 & 2.49 & $\begin{array}{r}.2193 \\
(.2243\end{array}$ & $\begin{array}{l}.2193 \\
.2243)\end{array}$ \\
\hline
\end{tabular}

$\operatorname{MED}_{i}$ as $c_{11, i}+1, i=1,2,3,4,5$. That is, $\widehat{\operatorname{MED}}_{1}=2, \widehat{\operatorname{MED}}_{2}=5, \widehat{\operatorname{MED}}_{3}=2, \widehat{\operatorname{MED}}_{4}=4$ and $\widehat{\mathrm{MED}}_{5}=1$. The adjusted $p$-value associated with this conclusion is $p_{10}=0.0000$. Second, the test based on Helmert contrasts also stops at the 11th step, but the results are $\widehat{\mathrm{MED}}_{1}=2$, $\widehat{\mathrm{MED}}_{2}=5, \widehat{\mathrm{MED}}_{3}=2, \widehat{\mathrm{MED}}_{4}=3$, and $\widehat{\mathrm{MED}}_{5}=1$, and the corresponding approximate $p$ value is $p_{10}=0.0224$, where the exact $p$-value is $p_{10}=0.0240$. The sequential testing results are further presented in table 4.

The conclusion by using the step-down procedures for this set of data is finally obtained. For the two mixed-type opioids in groups 1 and 3, both the pairwise and Helmert tests identify the MED as the second dose level, $\mathrm{ED}_{20}$. For the other mixed-type opioid in group 4, the pairwise test identifies the MED as $\mathrm{ED}_{80}$, while the Helmert test identifies $\mathrm{ED}_{40}$ to be the MED. Moreover, both the tests find that, for the placebo in group 2, the MED is not under study, and claim that the first dose level, $\mathrm{ED}_{10}$, is the MED for the opioid antagonist in group 5.

\section{Monte Carlo study}

We conducted a Monte Carlo study to compare the two procedures proposed in section 3 . In the study, $r$, the number of groups was fixed at five, and $c$, the number of dose levels excluding control was fixed at four. A common sample size, $n$, was assumed in each group by dose combination. The standard error of the means, $\sigma / \sqrt{n}$, was fixed at one. The d.f., $f$, was assumed to be $\infty$, using $\alpha=0.05$. For convenience, the critical constants for $\alpha=0.05$ were computed by formula (8) with $\rho=\bar{\rho}=0.079$ for TP and $\rho=0.00011$ for TH. 
Without loss of generality, $\mu_{i o}$ was fixed at 0 for all $i=1, \ldots, r$. For the positive dose responses, we considered 16 configurations of monotone case which include step and linear responses, and another 12 configurations of nonmonotone case. For each configuration $\left(\mu_{i j}, i=1, \ldots, r, j=0,1, \ldots, c\right)$, the sample means $\bar{X}_{i j}$, which are independent $N\left(\mu_{i j}, 1\right)$ r.v.s, were generated using the RANNOR function in SAS. This was replicated 10,000 times for each of the 28 configurations. Table 5 contains the estimates of the FWE, which is the proportion of replications that identified a noneffective dose in at least one group, and the

Table 5. Estimated FWE and power for $\alpha=0.05, r=5$, and $c=4$.

\begin{tabular}{|c|c|c|c|c|c|c|c|c|c|c|}
\hline \multirow[b]{2}{*}{ Case } & \multirow{2}{*}{$\begin{array}{l}\mu_{10} \\
\mu_{20} \\
\mu_{30} \\
\mu_{40} \\
\mu_{50}\end{array}$} & \multirow{2}{*}{$\begin{array}{l}\mu_{11} \\
\mu_{21} \\
\mu_{31} \\
\mu_{41} \\
\mu_{51}\end{array}$} & \multirow{2}{*}{$\begin{array}{l}\mu_{12} \\
\mu_{22} \\
\mu_{32} \\
\mu_{42} \\
\mu_{52}\end{array}$} & \multirow{2}{*}{$\begin{array}{l}\mu_{13} \\
\mu_{23} \\
\mu_{33} \\
\mu_{43} \\
\mu_{53}\end{array}$} & \multirow{2}{*}{$\begin{array}{l}\mu_{14} \\
\mu_{24} \\
\mu_{34} \\
\mu_{44} \\
\mu_{54}\end{array}$} & \multirow[b]{2}{*}{ True MED } & \multicolumn{2}{|c|}{ FWE } & \multicolumn{2}{|c|}{ Power } \\
\hline & & & & & & & Pairwise & Helmert & Pairwise & Helmert \\
\hline \multirow[t]{5}{*}{1} & 0 & 0 & 0 & 0 & 5 & 4 & .0445 & .0491 & .2937 & .7721 \\
\hline & 0 & 0 & 0 & 0 & 5 & 4 & & & & \\
\hline & 0 & 0 & 0 & 0 & 5 & 4 & & & & \\
\hline & 0 & 0 & 0 & 0 & 5 & 4 & & & & \\
\hline & 0 & 0 & 0 & 0 & 5 & 4 & & & & \\
\hline \multirow[t]{5}{*}{2} & 0 & 0 & 0 & 5 & 5 & 3 & .0448 & .0466 & .3658 & .7628 \\
\hline & 0 & 0 & 0 & 5 & 5 & 3 & & & & \\
\hline & 0 & 0 & 0 & 5 & 5 & 3 & & & & \\
\hline & 0 & 0 & 0 & 5 & 5 & 3 & & & & \\
\hline & 0 & 0 & 0 & 5 & 5 & 3 & & & & \\
\hline \multirow[t]{5}{*}{3} & 0 & 0 & 5 & 5 & 5 & 2 & .0456 & .0477 & .4800 & .7437 \\
\hline & 0 & 0 & 5 & 5 & 5 & 2 & & & & \\
\hline & 0 & 0 & 5 & 5 & 5 & 2 & & & & \\
\hline & 0 & 0 & 5 & 5 & 5 & 2 & & & & \\
\hline & 0 & 0 & 5 & 5 & 5 & 2 & & & & \\
\hline \multirow[t]{5}{*}{4} & 0 & 5 & 5 & 5 & 5 & 1 & - & - & .8175 & .7133 \\
\hline & 0 & 5 & 5 & 5 & 5 & 1 & & & & \\
\hline & 0 & 5 & 5 & 5 & 5 & 1 & & & & \\
\hline & 0 & 5 & 5 & 5 & 5 & 1 & & & & \\
\hline & 0 & 5 & 5 & 5 & 5 & 1 & & & & \\
\hline \multirow[t]{5}{*}{5} & 0 & 0 & 0 & 0 & 5 & 4 & .0423 & .0449 & .4505 & .6096 \\
\hline & 0 & 0 & 0 & 5 & 5 & 3 & & & & \\
\hline & 0 & 0 & 5 & 5 & 5 & 2 & & & & \\
\hline & 0 & 5 & 5 & 5 & 5 & 1 & & & & \\
\hline & 0 & 5 & 5 & 5 & 5 & 1 & & & & \\
\hline \multirow[t]{5}{*}{6} & 0 & 0 & 0 & 5 & 5 & 3 & .0435 & .0446 & .4795 & .6259 \\
\hline & 0 & 0 & 0 & 5 & 5 & 3 & & & & \\
\hline & 0 & 0 & 5 & 5 & 5 & 2 & & & & \\
\hline & 0 & 5 & 5 & 5 & 5 & 1 & & & & \\
\hline & 0 & 5 & 5 & 5 & 5 & 1 & & & & \\
\hline \multirow[t]{5}{*}{7} & 0 & 0 & 0 & 5 & 5 & 3 & .0439 & .0474 & .4509 & .6771 \\
\hline & 0 & 0 & 0 & 5 & 5 & 3 & & & & \\
\hline & 0 & 0 & 5 & 5 & 5 & 2 & & & & \\
\hline & 0 & 0 & 5 & 5 & 5 & 2 & & & & \\
\hline & 0 & 5 & 5 & 5 & 5 & 1 & & & & \\
\hline \multirow[t]{5}{*}{8} & 0 & 0 & 0 & 5 & 5 & 3 & .0423 & .0436 & .5138 & .5906 \\
\hline & 0 & 0 & 0 & 5 & 5 & 3 & & & & \\
\hline & 0 & 5 & 5 & 5 & 5 & 1 & & & & \\
\hline & 0 & 5 & 5 & 5 & 5 & 1 & & & & \\
\hline & 0 & 5 & 5 & 5 & 5 & 1 & & & & \\
\hline
\end{tabular}


Table 5. Continued.

\begin{tabular}{|c|c|c|c|c|c|c|c|c|c|c|}
\hline \multirow[b]{2}{*}{ Case } & \multirow{2}{*}{$\begin{array}{l}\mu_{10} \\
\mu_{20} \\
\mu_{30} \\
\mu_{40} \\
\mu_{50}\end{array}$} & \multirow{2}{*}{$\begin{array}{l}\mu_{11} \\
\mu_{21} \\
\mu_{31} \\
\mu_{41} \\
\mu_{51}\end{array}$} & \multirow{2}{*}{$\begin{array}{l}\mu_{12} \\
\mu_{22} \\
\mu_{32} \\
\mu_{42} \\
\mu_{52}\end{array}$} & \multirow{2}{*}{$\begin{array}{l}\mu_{13} \\
\mu_{23} \\
\mu_{33} \\
\mu_{43} \\
\mu_{53}\end{array}$} & \multirow{2}{*}{$\begin{array}{l}\mu_{14} \\
\mu_{24} \\
\mu_{34} \\
\mu_{44} \\
\mu_{54}\end{array}$} & \multirow[b]{2}{*}{ True MED } & \multicolumn{2}{|c|}{ FWE } & \multicolumn{2}{|c|}{ Power } \\
\hline & & & & & & & Pairwise & Helmert & Pairwise & Helmert \\
\hline 9 & $\begin{array}{l}0 \\
0 \\
0 \\
0 \\
0\end{array}$ & $\begin{array}{l}0 \\
0 \\
0 \\
0 \\
0\end{array}$ & $\begin{array}{l}0 \\
0 \\
0 \\
0 \\
0\end{array}$ & $\begin{array}{l}8 \\
8 \\
8 \\
8 \\
8\end{array}$ & $\begin{array}{l}12 \\
12 \\
12 \\
12 \\
12\end{array}$ & $\begin{array}{l}3 \\
3 \\
3 \\
3 \\
3\end{array}$ & .0481 & .0479 & .9464 & .9521 \\
\hline 10 & $\begin{array}{l}0 \\
0 \\
0 \\
0 \\
0\end{array}$ & $\begin{array}{l}0 \\
0 \\
0 \\
0 \\
0\end{array}$ & $\begin{array}{l}4 \\
4 \\
4 \\
4 \\
4\end{array}$ & $\begin{array}{l}8 \\
8 \\
8 \\
8 \\
8\end{array}$ & $\begin{array}{l}12 \\
12 \\
12 \\
12 \\
12\end{array}$ & $\begin{array}{l}2 \\
2 \\
2 \\
2 \\
2\end{array}$ & .0405 & .0424 & .1271 & .3325 \\
\hline 11 & $\begin{array}{l}0 \\
0 \\
0 \\
0 \\
0\end{array}$ & $\begin{array}{l}4 \\
4 \\
4 \\
4 \\
4\end{array}$ & $\begin{array}{l}6 \\
6 \\
6 \\
6 \\
6\end{array}$ & $\begin{array}{l}8 \\
8 \\
8 \\
8 \\
8\end{array}$ & $\begin{array}{l}10 \\
10 \\
10 \\
10 \\
10\end{array}$ & $\begin{array}{l}1 \\
1 \\
1 \\
1 \\
1\end{array}$ & - & - & .4994 & .4792 \\
\hline 12 & $\begin{array}{l}0 \\
0 \\
0 \\
0 \\
0\end{array}$ & $\begin{array}{l}0 \\
0 \\
0 \\
4 \\
4\end{array}$ & $\begin{array}{l}0 \\
4 \\
4 \\
6 \\
6\end{array}$ & $\begin{array}{l}8 \\
8 \\
8 \\
8 \\
8\end{array}$ & $\begin{array}{l}12 \\
12 \\
12 \\
10 \\
10\end{array}$ & $\begin{array}{l}3 \\
2 \\
2 \\
1 \\
1\end{array}$ & .0415 & .0423 & .2224 & .3071 \\
\hline 13 & $\begin{array}{l}0 \\
0 \\
0 \\
0 \\
0\end{array}$ & $\begin{array}{l}0 \\
0 \\
0 \\
4 \\
4\end{array}$ & $\begin{array}{l}0 \\
0 \\
5 \\
6 \\
6\end{array}$ & $\begin{array}{l}0 \\
5 \\
5 \\
8 \\
8\end{array}$ & $\begin{array}{c}5 \\
5 \\
5 \\
10 \\
10\end{array}$ & $\begin{array}{l}4 \\
3 \\
2 \\
1 \\
1\end{array}$ & .0397 & .0443 & .2516 & .3504 \\
\hline 14 & $\begin{array}{l}0 \\
0 \\
0 \\
0 \\
0\end{array}$ & $\begin{array}{l}0 \\
0 \\
0 \\
4 \\
4\end{array}$ & $\begin{array}{l}0 \\
0 \\
4 \\
6 \\
6\end{array}$ & $\begin{array}{l}5 \\
5 \\
8 \\
8 \\
8\end{array}$ & $\begin{array}{c}5 \\
5 \\
12 \\
10 \\
10\end{array}$ & $\begin{array}{l}3 \\
3 \\
2 \\
1 \\
1\end{array}$ & .0398 & .0425 & .2183 & .3217 \\
\hline 15 & $\begin{array}{l}0 \\
0 \\
0 \\
0 \\
0\end{array}$ & $\begin{array}{l}0 \\
0 \\
0 \\
4 \\
4\end{array}$ & $\begin{array}{l}0 \\
5 \\
5 \\
6 \\
6\end{array}$ & $\begin{array}{l}5 \\
5 \\
5 \\
8 \\
8\end{array}$ & $\begin{array}{c}5 \\
5 \\
5 \\
10 \\
10\end{array}$ & $\begin{array}{l}3 \\
2 \\
2 \\
1 \\
1\end{array}$ & .0435 & .0448 & .3143 & .4014 \\
\hline 16 & $\begin{array}{l}0 \\
0 \\
0 \\
0 \\
0\end{array}$ & $\begin{array}{l}0 \\
5 \\
0 \\
0 \\
4\end{array}$ & $\begin{array}{l}5 \\
5 \\
0 \\
4 \\
6\end{array}$ & $\begin{array}{l}5 \\
5 \\
8 \\
8 \\
8\end{array}$ & $\begin{array}{c}5 \\
5 \\
12 \\
12 \\
10\end{array}$ & $\begin{array}{l}2 \\
1 \\
3 \\
2 \\
1\end{array}$ & .0423 & .0421 & .3568 & .4511 \\
\hline 17 & $\begin{array}{l}0 \\
0 \\
0 \\
0 \\
0\end{array}$ & $\begin{array}{l}0 \\
0 \\
0 \\
0 \\
0\end{array}$ & $\begin{array}{l}5 \\
5 \\
5 \\
5 \\
5\end{array}$ & $\begin{array}{l}0 \\
0 \\
0 \\
0 \\
0\end{array}$ & $\begin{array}{l}0 \\
0 \\
0 \\
0 \\
0\end{array}$ & $\begin{array}{l}2 \\
2 \\
2 \\
2 \\
2\end{array}$ & .0412 & .0454 & .4293 & .7129 \\
\hline 18 & $\begin{array}{l}0 \\
0 \\
0 \\
0 \\
0\end{array}$ & $\begin{array}{l}5 \\
5 \\
5 \\
5 \\
5\end{array}$ & $\begin{array}{l}5 \\
5 \\
5 \\
5 \\
5\end{array}$ & $\begin{array}{l}0 \\
0 \\
0 \\
0 \\
0\end{array}$ & $\begin{array}{l}0 \\
0 \\
0 \\
0 \\
0\end{array}$ & $\begin{array}{l}1 \\
1 \\
1 \\
1 \\
1\end{array}$ & - & - & .7789 & .6866 \\
\hline
\end{tabular}


Table 5. Continued.

\begin{tabular}{|c|c|c|c|c|c|c|c|c|c|c|}
\hline \multirow[b]{2}{*}{ Case } & \multirow{2}{*}{$\begin{array}{l}\mu_{10} \\
\mu_{20} \\
\mu_{30} \\
\mu_{40} \\
\mu_{50}\end{array}$} & \multirow{2}{*}{$\begin{array}{l}\mu_{11} \\
\mu_{21} \\
\mu_{31} \\
\mu_{41} \\
\mu_{51}\end{array}$} & \multirow{2}{*}{$\begin{array}{l}\mu_{12} \\
\mu_{22} \\
\mu_{32} \\
\mu_{42} \\
\mu_{52}\end{array}$} & \multirow{2}{*}{$\begin{array}{l}\mu_{13} \\
\mu_{23} \\
\mu_{33} \\
\mu_{43} \\
\mu_{53}\end{array}$} & \multirow{2}{*}{$\begin{array}{l}\mu_{14} \\
\mu_{24} \\
\mu_{34} \\
\mu_{44} \\
\mu_{54}\end{array}$} & \multirow[b]{2}{*}{ True MED } & \multicolumn{2}{|c|}{ FWE } & \multicolumn{2}{|c|}{ Power } \\
\hline & & & & & & & Pairwise & Helmert & Pairwise & Helmert \\
\hline 19 & $\begin{array}{l}0 \\
0 \\
0 \\
0 \\
0\end{array}$ & $\begin{array}{l}0 \\
0 \\
0 \\
0 \\
0\end{array}$ & $\begin{array}{l}5 \\
5 \\
5 \\
5 \\
5\end{array}$ & $\begin{array}{l}5 \\
5 \\
5 \\
5 \\
5\end{array}$ & $\begin{array}{l}0 \\
0 \\
0 \\
0 \\
0\end{array}$ & $\begin{array}{l}2 \\
2 \\
2 \\
2 \\
2\end{array}$ & .0448 & .0475 & .4744 & .7411 \\
\hline 20 & $\begin{array}{l}0 \\
0 \\
0 \\
0 \\
0\end{array}$ & $\begin{array}{l}5 \\
5 \\
5 \\
5 \\
5\end{array}$ & $\begin{array}{l}5 \\
5 \\
5 \\
5 \\
5\end{array}$ & $\begin{array}{l}5 \\
5 \\
5 \\
5 \\
5\end{array}$ & $\begin{array}{l}0 \\
0 \\
0 \\
0 \\
0\end{array}$ & $\begin{array}{l}1 \\
1 \\
1 \\
1 \\
1\end{array}$ & - & - & .8130 & .7080 \\
\hline 21 & $\begin{array}{l}0 \\
0 \\
0 \\
0 \\
0\end{array}$ & $\begin{array}{l}0 \\
0 \\
0 \\
5 \\
5\end{array}$ & $\begin{array}{l}0 \\
0 \\
5 \\
5 \\
5\end{array}$ & $\begin{array}{l}5 \\
5 \\
5 \\
0 \\
0\end{array}$ & $\begin{array}{l}0 \\
0 \\
0 \\
0 \\
0\end{array}$ & $\begin{array}{l}3 \\
3 \\
2 \\
1 \\
1\end{array}$ & .0413 & .0438 & .4621 & .6179 \\
\hline 22 & $\begin{array}{l}0 \\
0 \\
0 \\
0 \\
0\end{array}$ & $\begin{array}{l}0 \\
0 \\
5 \\
5 \\
5\end{array}$ & $\begin{array}{l}0 \\
5 \\
5 \\
5 \\
5\end{array}$ & $\begin{array}{l}5 \\
5 \\
0 \\
5 \\
5\end{array}$ & $\begin{array}{l}0 \\
0 \\
0 \\
0 \\
0\end{array}$ & $\begin{array}{l}3 \\
2 \\
1 \\
1 \\
1\end{array}$ & .0437 & .0439 & .5429 & .6058 \\
\hline 23 & $\begin{array}{l}0 \\
0 \\
0 \\
0 \\
0\end{array}$ & $\begin{array}{l}5 \\
0 \\
5 \\
0 \\
5\end{array}$ & $\begin{array}{l}6 \\
0 \\
6 \\
0 \\
6\end{array}$ & $\begin{array}{c}8 \\
0 \\
10 \\
5 \\
8\end{array}$ & $\begin{array}{c}10 \\
2 \\
8 \\
8 \\
10\end{array}$ & $\begin{array}{l}1 \\
4 \\
1 \\
3 \\
1\end{array}$ & .0389 & .0397 & .0877 & .1664 \\
\hline 24 & $\begin{array}{l}0 \\
0 \\
0 \\
0 \\
0\end{array}$ & $\begin{array}{l}0 \\
0 \\
0 \\
0 \\
4\end{array}$ & $\begin{array}{l}6 \\
0 \\
6 \\
4 \\
5\end{array}$ & $\begin{array}{c}8 \\
0 \\
12 \\
6 \\
8\end{array}$ & $\begin{array}{c}12 \\
0 \\
10 \\
8 \\
12\end{array}$ & $\begin{array}{l}2 \\
5 \\
2 \\
2 \\
1\end{array}$ & .0431 & .0465 & .3505 & .4534 \\
\hline 25 & $\begin{array}{l}0 \\
0 \\
0 \\
0 \\
0\end{array}$ & $\begin{array}{l}0 \\
0 \\
0 \\
0 \\
4\end{array}$ & $\begin{array}{l}5 \\
0 \\
4 \\
0 \\
5\end{array}$ & $\begin{array}{l}5 \\
0 \\
6 \\
4 \\
8\end{array}$ & $\begin{array}{c}8 \\
0 \\
5 \\
8 \\
10\end{array}$ & $\begin{array}{l}2 \\
5 \\
2 \\
3 \\
1\end{array}$ & .0415 & .0448 & .1859 & .3417 \\
\hline 26 & $\begin{array}{l}0 \\
0 \\
0 \\
0 \\
0\end{array}$ & $\begin{array}{l}0 \\
0 \\
0 \\
0 \\
4\end{array}$ & $\begin{array}{l}6 \\
0 \\
6 \\
0 \\
5\end{array}$ & $\begin{array}{c}8 \\
0 \\
12 \\
5 \\
8\end{array}$ & $\begin{array}{c}12 \\
0 \\
10 \\
5 \\
12\end{array}$ & $\begin{array}{l}2 \\
5 \\
2 \\
3 \\
1\end{array}$ & .0430 & .0464 & .4480 & .5500 \\
\hline 27 & $\begin{array}{l}0 \\
0 \\
0 \\
0 \\
0\end{array}$ & $\begin{array}{l}0 \\
0 \\
0 \\
0 \\
4\end{array}$ & $\begin{array}{l}4 \\
0 \\
4 \\
0 \\
6\end{array}$ & $\begin{array}{l}6 \\
0 \\
8 \\
0 \\
6\end{array}$ & $\begin{array}{l}8 \\
0 \\
5 \\
5 \\
8\end{array}$ & $\begin{array}{l}2 \\
5 \\
2 \\
4 \\
1\end{array}$ & .0422 & .0458 & .1761 & .3134 \\
\hline 28 & $\begin{array}{l}0 \\
0 \\
0 \\
0 \\
0\end{array}$ & $\begin{array}{l}0 \\
0 \\
0 \\
0 \\
4\end{array}$ & $\begin{array}{l}6 \\
0 \\
6 \\
0 \\
5\end{array}$ & $\begin{array}{c}8 \\
0 \\
12 \\
0 \\
8\end{array}$ & $\begin{array}{c}12 \\
0 \\
10 \\
5 \\
12\end{array}$ & $\begin{array}{l}2 \\
5 \\
2 \\
4 \\
1\end{array}$ & .0444 & .0475 & .4308 & .5378 \\
\hline & ge po & & & & & & & & .4274 & .5545 \\
\hline
\end{tabular}


estimates of the power, which is the proportion that identified the true MED vector. This table also includes the average powers which can be used to compare the power performances of the two tests over all the configurations considered in the study. Note that the configurations with true MED vector $=\mathbf{1}$ involve no type I error, and hence the entry of estimated FWE $=.000$ is omitted for all procedures.

First, from the simulation results, we note that all two procedures control the FWE quite accurately at the nominal $\alpha=.05$ under all partial null configurations. (Recall that the estimated FWE must exceed $.05+1.96 \sqrt{.05 \times .95 / 10,000}=.0543$ in order to conclude that it is significantly different from [higher than] $\alpha=.05$.)

Next, looking at the estimates of the power, we see that TP has higher power than TH only when the true MED vector $=1$ (i.e. cases 4, 11, 18 and 20), otherwise the TH test is better than the TP test. This is as expected since the pairwise contrasts are good for detecting low MEDs, whereas Helmert contrasts are good for detecting high MEDs. Also, it is worth noting that their relative performances are not affected by the true type of response function (monotone $v s$. nonmonotone or linear $v s$. step). Finally, on an average, the TH test gains about $30 \%$ more power than the TP test.

\section{Conclusions}

In this paper, we develop two step-down closed procedures based on pairwise and Helmert contrasts for simultaneous identifications of MEDs in each of several groups while maintaining control of familywise error rate FWE strongly. We described how to obtain close approximations for the critical constants and $p$-values of the proposed procedures using the PROBMC function in SAS. A simulation study including both monotone and nonmonotone configurations was conducted to compare the two procedures. We note that both procedures control the FWE quite accurately under all partial null configurations. Also, we observed that $\mathrm{TP}$ has higher power than TH when MED $=1$ in each group, otherwise the TH test is better than the TP test. And these general trends are not affected by the type of the response function. On an average, the TH test is better than the TP test.

In the present study, we considered the equal sample size case, and its conclusions need to be generalized to the unequal sample size case. Although unequal sample sizes make the correlations $\rho_{j j^{\prime}}$ unequal for both pairwise and Helmert contrasts (in particular, the Helmert contrasts are no longer uncorrelated), whereas this causes no difficulty because exact integration methods exist for the calculations of the required critical constants and $p$-values, or, alternatively, they can still be approximately calculated by formulas (8) and (9), respectively, using the average correlation $\bar{\rho}$.

Finally, we note that this study has assumed that the observations are normally distributed. It is possible that the normal assumption is not reasonable or the sample sizes are too small to rely on the central limit theorem for normality, in which case nonparametric procedures are necessary [12].

\section{Acknowledgements}

The authors wish to thank the associate editor and a referee for their suggestions for improving the clarity of the exposition. The research of the first author was partially supported by National Science Council Grant NSC-89-2118-M-033-002. 


\section{References}

[1] Ruberg, S.J., 1989, Contrasts for identifying the minimum effective dose. Journal of the American Statistical Association, 84, 816-822.

[2] Dunnett, C.W., 1955, A multiple comparison procedure for comparing several treatments with a control. Journal of the American Statistical Association, 50, 1096-1121.

[3] Williams, D.A., 1971, A test for differences between treatment means when several dose levels are compared with a zero dose level. Biometrics, 27, 103-117.

[4] Williams, D.A., 1972, The comparison of several dose levels with a zero dose control. Biometrics, 28, 519-531.

[5] Marcus, R., Peritz, E., and Gabriel, K.R., 1976, On closed testing procedures with special reference to ordered analysis of variance. Biometrika, 63, 655-660.

[6] Tamhane, A.C., Hochberg, Y., and Dunnett, C.W., 1996, Multiple test procedures for dose finding. Biometrics, 52, 21-37.

[7] Cheung, S.H. and Holland, B., 1991, Extension of Dunnett's multiple comparison procedure to the case of several groups. Biometrics, 47, 21-32.

[8] Cheung, S.H. and Holland, B., 1992, Extension of Dunnett's multiple comparison procedure with differing sample sizes to the case of several groups. Computational Statistics and Data Analysis, 14, 165-182.

[9] Cheung, S.H. and Holland, B., 1994, A step-down procedure for multiple tests of treatment versus control in each of several groups. Statistics in Medicine, 13, 2261-2267.

[10] Dunnett, C.W. and Tamhane, A.C., 1991, Step-down multiple tests for comparing treatments with a control in unbalanced one-way layouts. Statistics in Medicine, 10, 939-947.

[11] Wright, S.P., 1992, Adjusted p-values for simultaneous inference. Biometrics, 48, 1005-1013.

[12] Jan, S.L. and Chen, Y.I., 2004, Nonparametric procedures for simultaneous identification of the minimum effective dose in each of several groups. Journal of Biopharmaceutical Statisticas, 14, 781-789.

[13] Hochberg, Y. and Tamhane, A.C., 1987. Multiple Comparison Procedures (New York: 21 John Wiley \& Sons); pp. 374-375.

[14] Johnson, N.L. and Kotz, S., 1972, Distributious in Statistics: Continuous Multivariate Distributions. (New York: John Wiley \& Sons); p. 134.

[15] Somerville, P.N., 1997, Multiple testing and simultaneous confidence intervals: calculation of constants. Computational Statistics and Data Analysis, 25, 217-223.

[16] Somerville, P.N., 1998, Numerical computation of multivariate normal and multivariate $t$ probabilities over convex regions. Journal of Computational and Graphical Statistics, 7, 529-545.

[17] Somerville, P.N., 1999, Critical values for multiple testing and comparisons: one step and step down procedures. Journal of Statistical Planning and Inference, 82, 129-138.

[18] Genz, A. and Bretz, F., 1999, Numerical computation of the multivariate $t$ probabilities with application to power calculation of multiple contrasts. Journal of Statistical Computation and Simulation, 63, 361-378.

[19] Genz, A. and Bretz, F., 2000, Numerical computation of critical values for multiple comparison problem. ASA Proceedings of the Statistical Computing Section, 84-87.

[20] Genz, A. and Bretz, F., 2002, Comparison of methods for the computation of multivariate $t$-Probabilities. Journal of Computational and Graphical Statistics, 11, 950-971.

[21] Royen, T., 1987, An approximation for multivariate normal probabilities of rectangular regions. Statistics, 18, 389-400.

[22] Iyengar, S., 1988, Evaluation of normal probabilities of symmetric regions. SIAM Journal on Scientific and Statistical Computing, 9, 418-423.

[23] Iyengar, S. and Tong, Y.L., 1989, Convexity properties of elliptically contoured distributions with applications. Sankhyā, 51, 13-29.

[24] Hsu, J.C., 1992, The factor analytic approach to simultaneous inference in the general linear model. Journal of Computational and Graphical Statistics, 1, 151-168.

[25] Mager, P.P., 1991, Design Statistics in Pharmacochemistry (New York: John Wiley \& Sons). 